Down Syndrome Research and Practice Vol. 5, No. 2, pp 63 - 70.

(c) The Down Syndrome Educational Trust

Printed in Great Britain. All Rights Reserved.

ISSN: 0968-7912 (1998) 5:2

\title{
REFERENCE AND REPRESENTATION IN CHILDREN WITH DOWN SYNDROME
}

\author{
Lois Moore*, John Clibbens and Ian Dennis \\ University of Plymouth, UK.
}

\begin{abstract}
To maintain coherent discourse linguistic and non-linguistic information must be integrated using a mental representation of current discourse. The ability of children with Down syndrome to use mental representations in discourse was assessed in this study by investigating the use of referential forms using a narrative task. The narratives produced by children with Down syndrome were compared with those of typically developing children. The influence of certain contextual features on the ability of children with Down syndrome to use pronouns and other referential forms was also investigated. These features included: the relative status of the characters, the number of characters in the story, the method of presenting the story, and the position of a listener while narrating the story.

Findings from this study indicate that typically developing children use a particular referential strategy when narrating a story. Children with Down syndrome do not use the same referential strategy. At a local level children with Down syndrome seem able to integrate sources of information in a mental representation of the discourse, but difficulty arises at a more general level.
\end{abstract}

Keywords: Down syndrome, language, children

* Now at MRC Institute of Hearing Research, Nottingham, UK.

\section{Introduction}

Extensive research has investigated and described language development in children and adults with Down syndrome. This research has concluded that children with Down syndrome perform more poorly on measures of productive language than on measures of language comprehension. Grammatical forms are found to be particularly hard to acquire and use by children and adults with Down syndrome (Rondal, 1988; Fowler, 1990). Grammatical forms are largely abstract features of language, which convey specific information. It is possible for such aspects of the language to be omitted while meaning on a very general level remains intact. However, specific information, which enables coherent discourse to be maintained, can often be lost. An inability to develop and use grammatical forms may be a purely linguistic problem or one which results from problems with other cognitive processes.
Maintaining coherent discourse depends on the ability to integrate numerous sources of information. The information includes: shared knowledge between interlocutors, access to world knowledge, short term memory for preceding discourse, and an understanding of linguistic strategies and linguistic forms - at a syntactic and semantic level. It is the ability to integrate sources of information and process information sequentially which has previously been noted to be problematic for children with Down syndrome in non-linguistic tasks (e.g. Elliot et al, 1987; Hartley, 1985; Kernan, 1990). The inability to use grammatical forms may therefore be related to problems associated with maintaining information within a mental representation: this also relies heavily on both long term and short term memory resources, which is also known to be deficient in children with Down syndrome (e.g. Marcell \& Armstrong, 1982). 
The present research investigated possible underlying reasons why children with Down syndrome find the use of grammatical forms difficult. In particular we investigated whether the problem was purely linguistic, or also related to other cognitive processes. We focused on the use of pronouns and other referential forms as the use of referential forms provides a good example of the way in which the sources of information mentioned above must be integrated in order for coherent discourse to be maintained.

The way in which typically developing children acquire the ability to use referential forms has been extensively investigated (e.g. KarmiloffSmith, 1985; Bamberg, 1986; Clibbens, 1992). Karmiloff-Smith (1985) identified a U-shaped developmental curve denoting the success with which typically developing children use referential forms to distinguish the status of characters - references to the main character are usually reduced referential forms (e.g. pronoun: "he"), and references to the peripheral characters are full (e.g. definite noun phrase: "the rabbit"). She suggested that their successful use and understanding depends on the information being represented and reorganised. In the specific narrative task used by Karmiloff-Smith, children of approximately four years old used mainly reduced referential forms in an ambiguous fashion, but by the age of seven, typically developing children became aware of rules governing the use of referential forms, and their use became highly structured and restricted. Use of reduced referential forms was exclusively reserved for the main character in a story, while full forms were used for peripheral characters; Karmiloff-Smith termed this the "Thematic Subject Constraint”. At nine years old, children were able to use referential forms more flexibly. That is to say, while the rules acquired at seven years old governed the referential forms used, other factors - such as context - were being taken into account and referential forms chosen accordingly.

Contextual features which may be taken as important influences over the referential form to be used are such things as whether the listener has access to the same knowledge as the speaker. In the case of story-telling, it is possible that if the listener cannot see the story-book the speaker will use full referential forms for all characters to avoid ambiguity (Emslie \& Stevenson, 1981). It is therefore possible that children with Down syndrome fail to maintain coherent discourse because they are not able to take account of their interlocutor's needs. The way in which the story is presented has also been shown to influence the referential forms used
(Spinillo \& Pinto, 1994). In addition to these contextual features, the effect of varying the status of the characters on the referential forms used was also investigated in this study. This was achieved by maximising the difference between main and peripheral characters in some stories, whilst in others the differentiation between main and peripheral characters was less distinct. It is suggested that in order to use referential forms strategically (as outlined above) a mental representation of the story must be constructed into which each of the sources of information can be integrated. Without the ability to construct and maintain information in a mental representation referential forms cannot be used flexibly and strategically.

The paper reports on two studies, each involved different videos which tested slightly different conditions. Each study also involved different children with Down syndrome and compared their performance on the narrative tasks with that of typically developing children.

\section{Method \\ Participants}

\section{Study 1}

40 children with Down syndrome, whose ages ranged from 5 to 18 years, volunteered to take part in this research project. Children attended either mainstream schools or schools for mild to moderate learning difficulties in the Devon and Somerset areas. All children with Down syndrome who attended co-operating schools, and who were permitted to take part, were included. 45 randomly selected typically developing children also participated, 15 fiveyear-olds, 15 seven-year-olds, and 15 ten-yearolds, from a mainstream primary school in Devon.

\section{Study 2}

Another sample of 40 children with Down syndrome, whose ages ranged from 5 to 18 years, volunteered to take part in this research project. Children attended either mainstream schools or schools for mild to moderate learning difficulties in the Devon and Avon areas. All children with Down syndrome who attended co-operating schools, and who were permitted to take part, were included. As with study one, 45 randomly selected typically developing children also participated, 15 five-year-olds, 15 seven-yearolds, and 15 ten-year-olds, from a mainstream primary school in Devon. 


\section{Procedure}

The procedure for both studies was identical, where changes occurred these will be specified below. A narrative task was used to obtain a controlled speech sample which would include referential forms. Each child was seen individually for approximately 30 minutes. Stories were presented on a video monitor, and the children were asked to narrate the story as they watched it. Each child saw four videos, each lasting for approximately four minutes. There were two ways in which the procedure varied in the two studies. First, the person who listened to the children telling the story was not the same in both studies. In study one the experimenter listened to the child narrating, in the second study a child known to the narrating child listened. Second, the type of story was not the same for both studies, because different contextual features were tested in each study; these are explained below.

Videos seen by children in study one investigated:

Character Status. All stories contained one main character and two peripheral characters; the referential forms used for each character were assessed to ascertain whether children were able to distinguish the status of each, and mark that distinction linguistically (for example by using reduced references for main characters and/or full references for peripheral characters).

Moving or Still. The presentation was varied the characters were either moving, as is usual in a video, or still as in a story-book presentation.

Listener Position. The listener - who was the experimenter - was either in a position where they could or could not see the story while the child narrated the story.

Videos seen by children in study two investigated:

Character Status. The importance of status was assessed. Stories contained either one or two peripheral characters and one main character. Those stories with one peripheral character were included to maximise the difference between character status.

Listener Position. The listener - who was another child- was either in a position where they could or could not see the story while the child narrated the story.

Questions. After each video the child was asked a series of questions in order to further assess what status the child had assigned to each character:

* Who was the story about?

* Who was the most important person?

* Who was in the story for longest?

* Who was the main person in the story?

Each child was also assessed using two receptive language measures, one to measure vocabulary British Picture Vocabulary Scale (BPVS) (Dunn and Dunn, 1982); and one to measure understanding of grammar - Test for the Reception of Grammar (TROG) (Bishop, 1983). A non-verbal measure was also used, widely accepted as a good test of general cognitive ability - Raven's Coloured Progressive Matrices (Raven, 1963). It was hoped that language and cognitive age-equivalent scores could be obtained in order to match children with Down syndrome with typically developing children, however this was not possible as an age-equivalent score could not be derived for many of the children with Down syndrome.

Each child was video-recorded while they narrated each video. This was to allow each story to be transcribed, to include any pointing and signing which might accompany the verbal narration. Each referential form used in each narration was then coded for each character, these were divided into three categories. First, an initial reference to the character - where the child is introducing the character into the story. Second, a continuing reference to the character, where no reference is made to another character. Third, a re-establishing reference, where the character must be re-established as the current focus of attention, after another character has been previously referenced. The references were also divided into full references (indefinite noun phrases, definite noun phrases, noun phrases which did not contain a determiner) or reduced references (pronouns, nominal substitute, zero anaphora). For the purposes of the analyses, only the use of full references was assessed.

\section{Results}

Example of a narrative produced by $\mathrm{R}$, female, age 12 .

While results from typically developing children raised some interesting points, the results presented here focus predominantly upon the performance of children with Down syndrome, using typically developing children as a comparison group. Analysis of the results of the narrative task make use of the calculated proportion of full references used by each child in each video. It was not possible to carry out appropriate matching of children with Down syndrome with typically developing children, 
The main character is a Rabbit, and the story has one peripheral character - a teddy. The listener is not watching the screen.

\section{E: what's happening?}

R: a rabbit, he cleaning his shelf, and rubbing his till, and rubbing his counter, and he went back, pick up the cake, put it on the shelf, then he pick up another cake, he put it on the shelf next to the big one, and the last cake with icing on and put it next to that thing, after that he went back to get another cake and put it up high, and he can't put it up high. Here comes the bear, baking the big cake, and then he went back to get a little cake and the bear is so greedy, he says thanks to him. The he went back again, then close up the till, and went back to the shelf. Then he came back with a chair and put it in front of the shelf, on the counter really, picking the cake, then he get up on the chair and put it next to the little one, then he went back down again and pick up the chair - I think he's turning it round. Up it goes, and put it on the counter in front of the till. And then he sits down to have a sleep.

\section{A description of the same story:}

A rabbit enters the shop with a duster. She dusts the shelves, the till, and the counter. She sees the cakes on the counter and looks at the shelves, then she leaves. She returns and goes over to move the cakes on the counter. She moves them individually - four small cakes and one large one. There is no room for the large cake on the lower shelves so she tries to reach the top shelf. But she cannot reach however much she tries. Just then a teddy enters the shop so the rabbit puts the large cake down by the till. They both wave and the teddy puts his money on the counter. The rabbit goes to get the large cake, but the teddy shakes his head and points to the small cakes on the shelf. The rabbit looks at the small cakes and nods. She goes to get one and puts it on the counter by the teddy. The teddy then picks it up and leaves while the rabbit is picking up the money. They wave goodbye. The rabbit puts the money in the till and then turns round to look at the big cake which has been left on the counter. She leaves the shop and returns with a chair which she carefully positions by the shelf. She then goes to pick up the large cake and carefully climbs onto the chair so that she can reach to put the large cake on the top shelf. Once she has put the cake on the shelf she picks up the chair and puts it in front of the till. She yawns and then slumps down on the chair and falls asleep after her busy day.

\begin{tabular}{|c|c|c|c|c|}
\hline & $\begin{array}{l}\text { Chronological } \\
\text { Age }\end{array}$ & $\begin{array}{l}\text { Cognitive Age } \\
\text { (Raven's) }\end{array}$ & BPVS Age & TROG Age \\
\hline \multicolumn{5}{|l|}{ Study One } \\
\hline Down syndrome & 119 & 62 & 55 & 48 \\
\hline Five-year-olds & 63 & 63 & 72 & 64 \\
\hline Seven-year-olds & 89 & 90 & 100 & 80 \\
\hline Ten-year-olds & 124 & 132 & 131 & 132 \\
\hline \multicolumn{5}{|l|}{ Study Two } \\
\hline Down syndrome & 138 & 50 & 48 & 51 \\
\hline Five-year-olds & 65 & 70 & 83 & 75 \\
\hline Seven-year-olds & 90 & 85 & 90 & 82 \\
\hline
\end{tabular}

based on scores from the standardised tests. However, it was possible to use the scores obtained by each child with Down syndrome to establish that there were no significant differences (using a t-test) between the language and cognitive skills of children in study one and those in study two. Any differences in performance on the narrative task are likely to be due to changes made to the task (see Table 1. for details of chronological age, language age, and cognitive age for each group of children). One of the most surprising findings, contrary to predictions made by Stevenson (1988), was that the position of the listener when the child narrated the story had no effect on the referential forms used. Since no differences were found this is not reported on in the following results. 


\section{Initial References to Characters}

Both children with Down syndrome and typically developing children used mainly full references as initial references to both the main and peripheral characters, contextual variables did not alter this strategy. An analysis of variance (for study one the analysis involved a 4 (subject group) x 2 (character type) x 2 (video type) analysis of variance; for study two a 4 (subject group) $\mathrm{x} 2$ (character type) $\mathrm{x} 2$ (number of peripheral characters) analysis of variance was used), which looked at the proportion of full references used by children with Down syndrome and typically developing children, showed there to be no significant differences between the performance of children with Down syndrome and that of typically developing children. This was the case for both studies.

\section{Continuing References to Characters}

For continuing references to characters, where the same character remains the central focus of the story and no other character has been mentioned, children with Down syndrome and typically developing children use mainly reduced references in each video type and for each character. Using analysis of variance it was possible to compare the proportions of full references used by each subject group for each study, these are reported separately below. For study one the analysis involved a 4 (subject group) x 2 (character type) x 2 (video type) analysis of variance; for study two a 4 (subject group) $\mathrm{x} 2$ (character type) $\mathrm{x} 2$ (number of peripheral characters) analysis of variance was used.

\section{Study 1}

The character being referred to affected the proportion of full references used $(\mathrm{F}=71 ; \mathrm{df}=$ 81; $\mathrm{p}<0.001)$, as did the type of video $(\mathrm{F}=$ 3.3; $\mathrm{df}=81 ; \mathrm{p}<0.05)$. Newman-Keuls post hoc tests identified that children with Down syndrome in study one made no distinction between the characters in either type of video (references to characters in moving videos: $\mathrm{p}=$ 0.8 ; those in still videos: $\mathrm{p}=0.6$ ).

\section{Study 2}

As with study one, the character being referred to affected the proportion of full references used $(\mathrm{F}=74.9 ; \mathrm{df}=81 ; \mathrm{p}<0.001)$. The number of peripheral characters also affected the proportion of full references used $(\mathrm{F}=8.4 ; \mathrm{df}=81 ; \mathrm{p}<$ $0.01)$. Newman-Keuls post hoc tests also showed that children with Down syndrome in study two distinguished between the characters at a level which approached significance $(\mathrm{p}<0.07)$.
Using Newman-Keuls post hoc tests some differences were found between children with Down syndrome and typically developing children. Typically developing children in studies one and two used significantly fewer full references for the main character than for the peripheral characters (at a significance level of $\mathrm{p}$ $<0.01$ in each case).

\section{Re-establishing References to Characters}

Re-establishing references are necessary when the focus of attention has changed and the child must clearly indicate to the listener the character who is now the focus of attention. This is usually achieved by using a full reference to avoid ambiguity for the listener. However, the status of the character may override such a necessity, as previously noted by Karmiloff-Smith (1985) and Clibbens (1992). Main characters are more likely to be referenced using a reduced referential form, and peripheral characters with a full referential form. Performance of typically developing children and children with Down syndrome was again analysed using Analysis of Variance for study one and two separately, assessing the proportion of full references used by each subject group. For study one the analysis involved a 4 (subject group) x 2 (character type) $\mathrm{x} 2$ (video type) analysis of variance; for study two a 4 (subject group) x 2 (character type) x 2 (number of peripheral characters) analysis of variance was used.

\section{Study 1}

For study one there were significant main effects of character $(\mathrm{F}=31.8$; $\mathrm{df}=81 ; \mathrm{p}<0.001)$, video type $(\mathrm{F}=38.7 ; \mathrm{df}=81 ; \mathrm{p}<0.001)$, and subject group $(\mathrm{F}=3.6 ; \mathrm{df}=81 ; \mathrm{p}<0.05)$. Results of planned orthogonal comparisons showed that fewer full references were used for the main character than for the peripheral character by typically developing children in both moving and still videos $(p<0.05)$, but no significant differences were found for the proportion of full references used for each character by children with Down syndrome. Children with Down syndrome did not distinguish between the characters using different referential forms in either video type, as can be seen in Figure 1.

\section{Study 2}

For study two there were significant main effects of number of peripheral characters $(\mathrm{F}=6.8$; $\mathrm{df}$ $=81 ; \mathrm{p}<0.01)$, and subject group $(\mathrm{F}=4 ; \mathrm{df}=$ 81; p < 0.01). Planned orthogonal comparisons showed that five-year-olds distinguished between 


\section{Figure 1: The proportion of full references used by each subject group for each character in each video type}

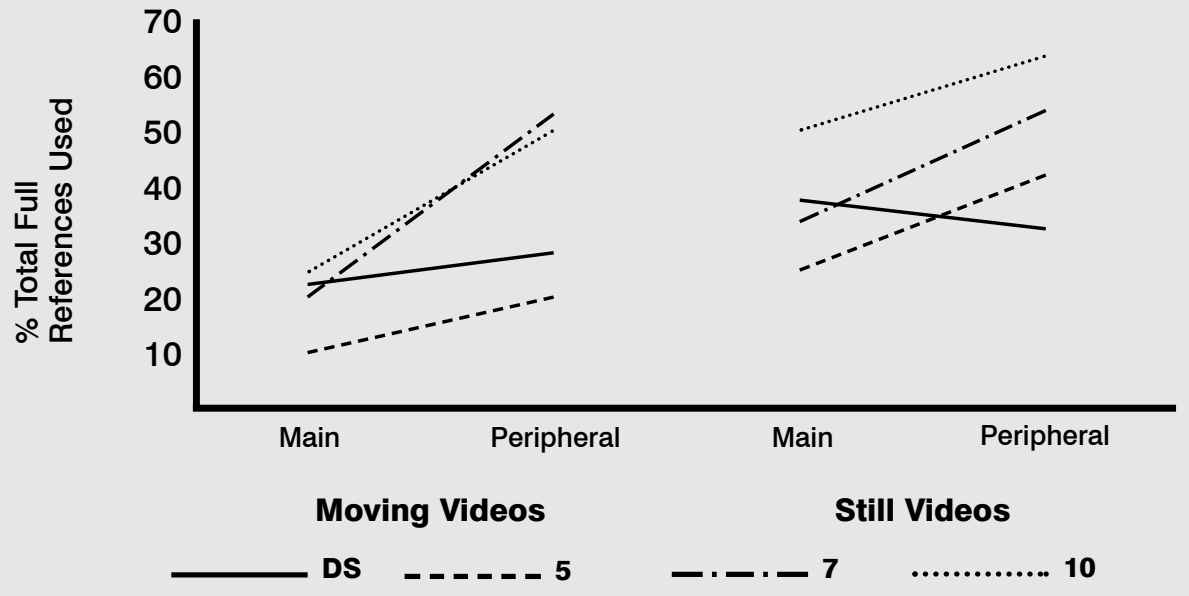

characters significantly only in the oneperipheral-character stories $(p=0.04)$. Sevenand ten-year-olds distinguished between characters significantly only in the twoperipheral-character stories. Seven-year-olds used fewer full references for the main character than for the peripheral character $(p<0.05)$, while ten-year-olds used fewer full references for the peripheral character $(\mathrm{p}<0.01)$. Results for children with Down syndrome showed that overall more full references were used for the main character than for the peripheral character $(\mathrm{p}<0.06)$. This difference was only significant in one-peripheral-character stories when the listener could not see the screen $(\mathrm{p}<0.05)$. This result therefore indicates that when the status of the characters was maximally different children with Down syndrome used more full references for the main character. Figure 2 shows the differences between the subject groups for each character in each video condition.

\section{Figure 2: The proportion of full references used by each subject group for each character in each video type}

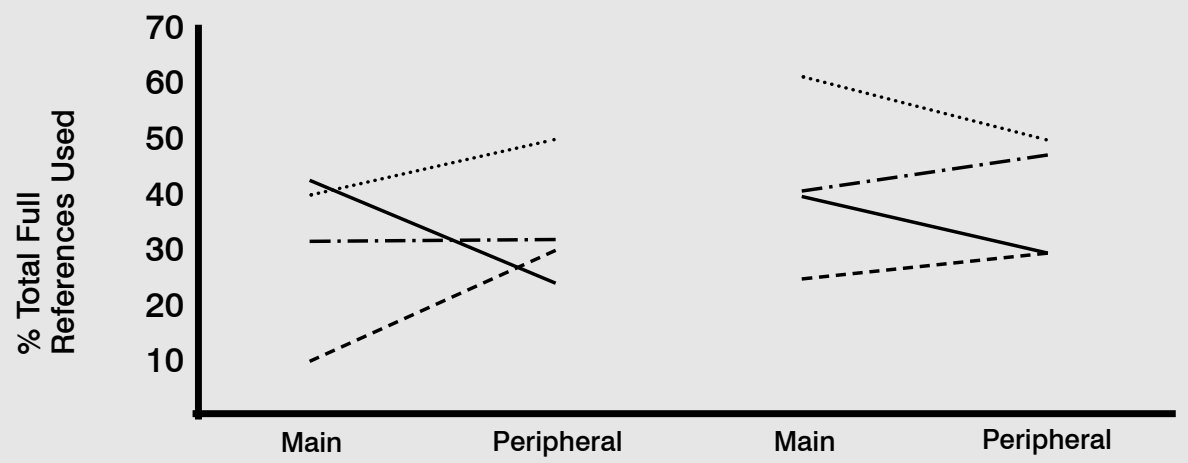

1PC

2PC 


\section{Conclusions}

Children with Down syndrome

demonstrated the ability to use referential forms in a similar way to typically developing children in both initial references and continuing references. In these reference types the ability to maintain information over an extended period in a mental representation of the story is not essential, it is necessary only to access limited amounts of information at a very local level. However, differences have been noted in reestablishing references where information such as listener's knowledge, previous mention of the characters, status of the characters, current focus of attention, must all be accessed, integrated and maintained in a mental representation of the story in order to use relevant referential forms appropriately and strategically.

Children with Down syndrome in study one demonstrated that while they were able to use the full range of referential forms they were not using them to distinguish between the characters. However, typically developing children, even as young as five years old, were able to use a thematic subject strategy with varying degrees of flexibility depending on age and context. There may be a number of reasons why children with Down syndrome were not able to use a thematic subject strategy. They may be unable to distinguish between the status of the characters at a representational level, or unable to use the necessary linguistic forms to mark the distinction, or they may lack understanding of what the listener needs to know.

Results of subjects in study two more clearly identified the underlying causes for difficulties experienced by children with Down syndrome. They were still unable to use a thematic subject strategy in stories containing two peripheral characters. However, when there is more limited information to be integrated - such as in stories which contain only one peripheral character where the distinction between the characters is maximally different - they are able to distinguish linguistically between the characters. The referential strategy is the opposite of the one used by typically developing children, indicating that the way in which status is encoded may still be different from that of typically developing children. Answers given to the questions which were asked regarding the status of the characters in the story also explored the ability to identify the main and peripheral characters. Whilst typically developing children were able to answer such questions flawlessly, children with Down syndrome did not perform above chance levels. This suggests that children with Down syndrome can form mental representations of discourse but have difficulty in using them efficiently. Referential forms can be used strategically where fewer items of information have to be integrated, indicating that although it may be possible to store and access each item of information individually, when more complicated discourse occurs which requires information to be maintained over a longer period children with Down syndrome experience difficulty.

It would seem that mental representations may not be used efficiently to integrate linguistic and cognitive information in order to successfully use a referential strategy to maintain coherent discourse, except in cases where fewer items of information are needed to be integrated. The results of this study indicate that further research is needed to specify the reasons why children with Down syndrome find representing status difficult, as well as why they use different referential strategies to indicate the character status. In terms of implications for long term intervention, these results suggest that children with Down syndrome can use complex grammatical forms successfully if relevant information is provided in a simplified format, with distinctions being made as clearly as possible, and with adequate time for accessing and maintaining information in a mental representation of the event. Bamberg (1986) was able to demonstrate that performance improved when the child was told the story on a regular basis at home and at school prior to the child having to narrate the story. It may therefore be possible to employ a training procedure to enhance the use of referential forms in a strategic manner.

\section{Correspondence:}

Lois Moore, MRC Institute of Hearing

Research, University Park, Nottingham, NG7 2RD (E-mail, lois@ihr.mrc.ac.uk)

Author Note: This paper was presented as a poster at the 2nd International Conference on Language and Cognitive Development in Down Syndrome, 8-10 April, 1997, Portsmouth, UK. 


\section{References}

Bamberg, M. (1986). A functional approach to the acquisition of anaphoric relations. Linguistics, 24 , 227-284.

Bishop, D. (1983). Test for the Reception of Grammar. Medical Research Council, Applied Psychology Unit, Cambridge.

Clibbens, J. (1992). Comprehension and production of discourse anaphora: a developmental study. Bloomington, IN: Indiana University Linguistics Club Publications.

Dunn, L. \& Dunn, L. (1982). British Picture Vocabulary Scale. Windsor: NFER-Nelson.

Elliot, D., Edwards, J., Weeks, D., Lindley, S. \& Carnahan, H. (1987). Cerebral specialisation in young adults with Down syndrome. American Journal of Mental Deficiency, 91, 480-485.

Emslie, H. \& Stevenson, R. (1981). Pre-school children's use of the articles in definite and indefinite referring expressions. Journal of Child Language, 8, 313-328.

Fowler, A. (1990). Language abilities in children with Down syndrome: evidence for a specific syntactic delay. In: D. Cicchetti \& M. Beeghly (Eds.) Children with Down's Syndrome: A Developmental Perspective. Cambridge: Cambridge University Press.

Hartley, X. (1985). Receptive language processing and ear advantage in Down's syndrome children. Journal of Mental Deficiency Research, 29, 170-182.

Karmiloff-Smith, A. (1985). Language and cognitive processes from a developmental perspective. Language and Cognitive Processes, 1, 61-85.

Kernan, K. (1990). Comprehension of syntactically indicated sequences by Down's syndrome and other mentally retarded adults. Journal of Mental Deficiency Research, 34, 169-178.

Marcell, M. \& Armstrong, V. (1982). Auditory and visual sequential memory of Down's syndrome and non-retarded children. American Journal of Mental Deficiency, 86, 86-95.

Raven, J. (1963). Raven's Coloured Progressive Matrices. Windsor: NFER-Nelson.

Rondal, J. (1988). Language development in Down's syndrome: a life-span perspective. International Journal of Behavioural Development, 11, 21-36.

Spinillo, A. \& Pinto, G. (1994). Children's narratives under different conditions: a comparative study. British Journal of Developmental Psychology, 12, 177-193.

Stevenson, R. (1988). Models of language development. Milton Keynes: Open University Press. 